\title{
A INFLUÊNCIA ANTRÓPICA NA EVOLUÇÃO SEMANAL DA TEMPERATURA DO AR NO BAIRRO MARACANÃ/RJ
}

\author{
Heitor Soares de Farias ${ }^{1}$, \\ Ana Maria de Paiva Macedo Brandão
}

\begin{abstract}
RESUMO
Este trabalho aborda o clima urbano no bairro Maracanã, localizado na zona norte da cidade do Rio de Janeiro, considerando suas características ambientais, padrões de uso do solo e dinamismo das atividades condicionadas aos padrões atmosféricos regionais atuantes, capazes de refletir na evolução semanal da temperatura do ar. Os dados diários de temperatura da estação meteorológica do Maracanã, no período de 1992 a 2002, foram separados por dia da semana e comparados com os dados de três estações de monitoramento da qualidade do ar de bairros vizinhos - São Cristóvão e Tijuca, além do Centro. A avaliação da influência antrópica neste ritmo foi feita em duas etapas: na primeira fez-se o cruzamento da curva de temperatura com a de concentração de CO para avaliar a interferência dos veículos na temperatura; já a segunda etapa verificou o aquecimento provocado por uma aglomeração de pessoas através de data loggers instalados no Estádio Maracanã monitorando a temperatura do ar por uma semana, e nesse período foi realizado um evento com um público superior a 50 mil pessoas, o primeiro jogo da final da Copa do Brasil de 2006 quando se enfrentaram Vasco e Flamengo. As quatro estações de monitoramento apresentaram uma evolução semanal para temperatura bastante semelhante, com dias úteis mais quentes e finais de semana menos quentes. No entanto não foi comprovada a interferência antropogênica nesse ritmo semanal.
\end{abstract}

Palavras-chave: temperatura do ar, microclima, Maracanã, Rio de Janeiro.

\begin{abstract}
This paper aims to study the urban climate in the quarter Maracanã, considering its environmental characteristics, patterns of land use and dynamism of the activities subject to regional atmospheric patterns acting, able to reflect on a weekly evolution of air temperature. The daily data of temperature of the meteorological station of the Maracanã, from 1992 to 2002, were separated by day and compared with data for three tracking stations air quality in neighboring districts - São Cristóvão and Tijuca, in addition to the Center. The evaluation

\footnotetext{
${ }^{1}$ Geógrafo, Mestre em Geografia/UFRJ e Doutorando em Geografia/UFF, heisofa@gmail.com
}

2 Geógrafa, Professora Doutora do Dep. de Geografia/UFRJ, abrandao@globo.com
\end{abstract}


human influence on this pace was made in two stages: the first was made at the intersection of the curve of temperature with the concentration of $\mathrm{CO}$ to evaluate the interference of vehicles in temperature; already the second step was the warming caused by an agglomeration of people through data loggers installed in the stadium Maracanã monitoring the air temperature for a week, and that time was a public event with a more than 50 thousand people, the first game of end of the Copa do Brasil, 2006 when they faced Vasco and Flamengo. The four monitoring stations showed a weekly rate for a similar temperature, with warmer days and the weekends less hot. However, no evidence of anthropogenic interference in this weekly rhythm.

Keywords: air temperature, microclimate, Maracanã, Rio de Janeiro.

\section{INTRODUÇÃO}

A qualidade da vida humana está diretamente relacionada com a interferência da obra do homem no meio natural. O homem urbano defronta-se com a impessoalidade da grande aglomeração e com a má qualidade do meio ambiente, geradas pela rápida transição da vida urbana metropolitana (LOMBARDO, 1985).

A partir do século XIX, as atividades humanas passaram a ter força dominante na mudança de composição da atmosfera em função da atividade industrial, que aumentou cerca de vinte vezes no século XX. A expansão da atividade industrial teve como conseqüências a explosão populacional nas áreas urbanas e o rápido aumento da utilização dos recursos com grande impacto no meio ambiente (BRANDÃO, 1992).

Ao longo de cinco milênios de organização urbana na face da Terra, nunca foram assumidas as proporções de expressão espacial e dinâmica funcional que caracterizam a organização urbana a partir dos meados do século $X X$. Seja pela implosão demográfica ou ainda pela explosão de atividades, "os espaços urbanos passaram a assumir responsabilidades do impacto máximo da atuação humana sobre a organização na superfície terrestre e na deterioração do ambiente" (MONTEIRO, 1976).

As áreas urbanas e, principalmente, as metropolitanas são as mais afetadas. Não só por corresponderem aos segmentos da superfície terrestre que foram mais intensamente transformados, mas, também, por concentrarem milhares de pessoas em pequenos espaços.

O aumento da densidade populacional nas grandes cidades contribui, também, para alterações no clima local. Imagina-se, naturalmente, que a magnitude do fluxo de radiação solar é infinitamente maior do que a capacidade de intervenção humana sobre o planeta. Entretanto, os moradores das metrópoles são submetidos a determinadas situações, como por exemplo, as aglomerações verificadas nos transportes de massa nos horários de rush, onde a densidade de pessoas por metro quadrado é tão grande que o efeito da energia dissipada pelos corpos naquele pequeno espaço pode ser comparável à magnitude da radiação solar sobre a Terra. (AZEVEDO, 2001)

Nesse sentido que, segundo Mendonça (2003), "o clima constitui-se numa das dimensões do ambiente urbano e seu estudo tem oferecido importantes contribuições ao equacionamento da questão ambiental das 
cidades." As condições climáticas destas áreas, entendidas como clima urbano, são derivadas da alteração da paisagem natural e da sua substituição por um ambiente construído, palco de intensas atividades humanas. O clima urbano é um sistema singular que abrange o clima de um dado espaço terrestre e sua urbanização, ou seja, a interação entre o clima local (fato natural) e a cidade (fato social) (MONTEIRO,1976).

Esta pesquisa justifica-se na medida em que visa contribuir com discussões sobre planejamento urbano, pois nas grandes cidades e áreas metropolitanas testemunha-se um crescimento com deficiências crônicas: crescem em proporção inversa a capacidade administrativa de planejá-las e dotá-las de infraestrutura. Estas cidades são a materialização de um desenvolvimento insustentável que não é compatível com a preservação do meio ambiente.

Considerando a problemática da cidade do Rio de Janeiro, suas características ambientais $\mathrm{e}$, considerando os padrões de uso do solo e dinamismo das atividades condicionadas aos padrões atmosféricos regionais atuantes, o presente estudo busca identificar a influência destes fatores, principalmente, se a energia liberada pelas atividades humanas é capaz de se refletir no ritmo semanal dos tipos de tempo.

\section{MATERIAL E MÉTODOS}

O município do Rio de Janeiro está situado a 22054'23" de latitude sul e 43010'21" de longitude oeste (Figura 1). Seu relevo é constituído de dois domínios fisiográficos: as montanhas e as áreas de baixadas. A área montanhosa engloba os maciços litorâneos, as serras, os morros isolados e as ilhas oceânicas; enquanto que a área de baixada corresponde a $75 \%$ de seu território.

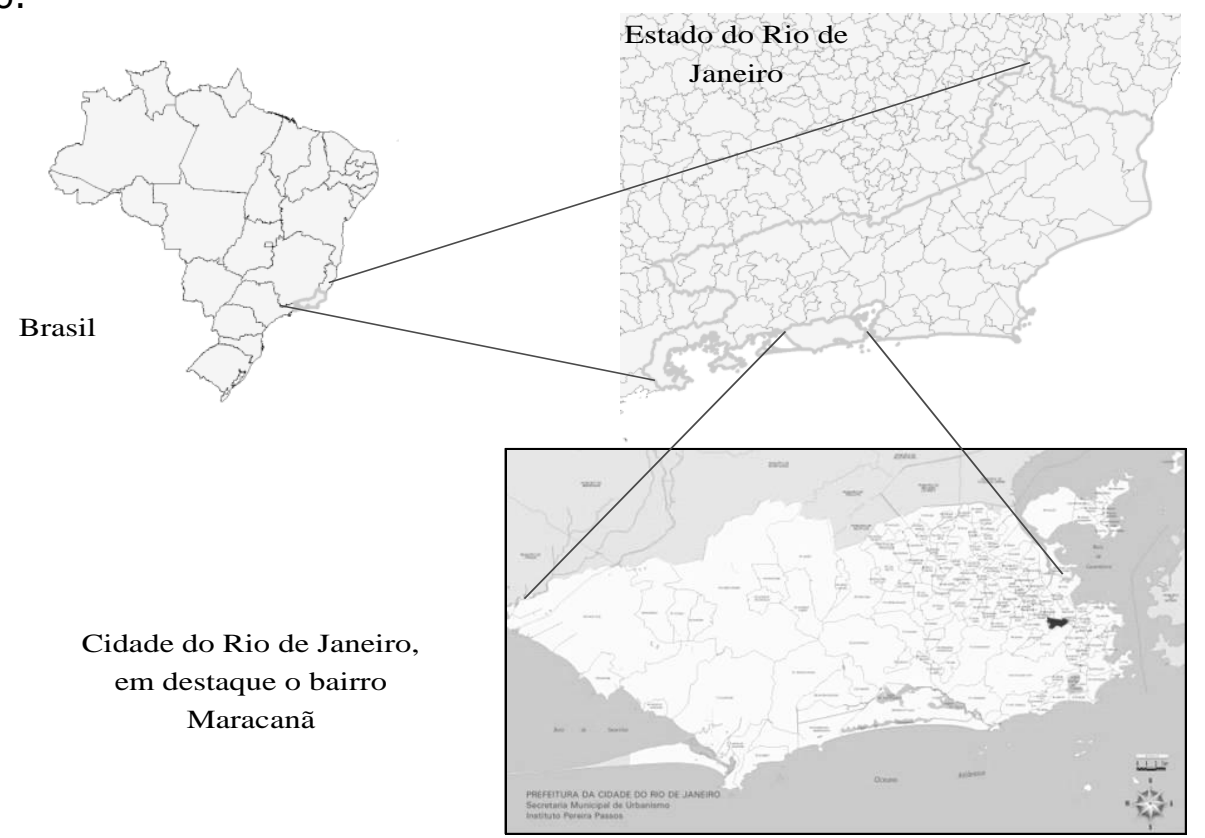

Figura 1 - A localização do bairro Maracanã -Zona Norte da Cidade do Rio de Janeiro 
A posição do bairro a sotavento do maciço da Tijuca, onde predominam as situações de calmaria, favorece ao aumento dos valores térmicos e à intensificação das situações de desconforto. Por esses motivos a qualidade do ar é, também, freqüentemente afetada revelando-se inadequada à saúde da população, principalmente, nos meses de inverno quando é maior a existência de situações meteorológicas de inversão térmica. (BRANDÃO, 1996).

O município do Rio de Janeiro tem $1.182 \mathrm{~km}^{2}$ e uma população de 6.094.183 habitantes, o que corresponde à densidade populacional de 5.156 $\mathrm{hab} / \mathrm{km}^{2}$. O bairro Maracanã é um exemplo de área com grande densidade populacional na Cidade do Rio de Janeiro. Com uma área territorial de 1,67 km² e população residente de 27.319 habitantes, sua densidade demográfica é de 16.358 habitantes por $\mathrm{km}^{2}$.

Embora com função basicamente residencial o bairro Maracanã oferece vários serviços públicos e infraestrutura de entretenimento, destacando-se o Hospital Pedro Ernesto, a Universidade do Estado do Rio de Janeiro, as Escolas Técnicas CEFET e CEFETEQ, e o famoso Complexo do Maracanã. Todas estas características ajudam a compor um uso do solo bastante diversificado que atrai um expressivo contingente de população flutuante, aumentando demasiadamente sua densidade populacional, o que suscita alguns questionamentos.

- Quais os possíveis efeitos desta característica no clima local, especialmente, no comportamento da temperatura?

- Considerando que o fluxo de veículos e de pessoas no bairro é mais intenso durante os dias úteis, há uma diferenciação da temperatura nos diferentes dias da semana?

- Uma grande aglomeração de pessoas reunidas em um mesmo espaço, como é o caso do estádio Maracanã com um grande público, é capaz de promover uma alteração considerável na temperatura, ainda que na escala local? Se positivo, o efeito poderá ser percebido no entorno próximo?

As questões levantadas orientaram a estratégia metodológica deste trabalho que foi dividida em etapas. Primeira etapa: obtenção dos dados diários da estação meteorológica localizada no bairro Maracanã, para confecção de gráficos da série histórica com onze anos de registros (1992 a 2002) da temperatura do ar visando a análise da evolução dos atributos do clima na área de estudo.

Segunda etapa: obtenção dos dados das estações de qualidade do ar junto à Secretaria de Meio Ambiente da Prefeitura da Cidade do Rio de Janeiro para confecção de gráficos a partir das médias diárias do primeiro trimestre do ano de 2002 de concentração de monóxido de carbono e sua comparação com os dados correspondentes de temperatura ar no mesmo período. O monóxido de carbono foi escolhido para avaliar o fluxo de carros em cada dia da semana, já que as estações de qualidade do ar não monitoraram a concentração de dióxido de carbono, gás estufa. Com estas informações objetiva-se identificar a interferência do fluxo de veículos no comportamento das temperaturas confrontando as curvas de variação da temperatura e de concentração de monóxido de carbono. Como mostra a figura 2 foram escolhidas as estações de São Cristóvão (situada no Campo de São Cristóvão), Tijuca (localizada na Praça Saes Peña) por serem as mais próximas das condições ambientais do bairro e Centro (situada no Largo da Carioca) por apresentar um ritmo de atividades 
bem marcante - bastante intenso de segunda à sexta-feira e com menor movimento no sábado e no domingo.

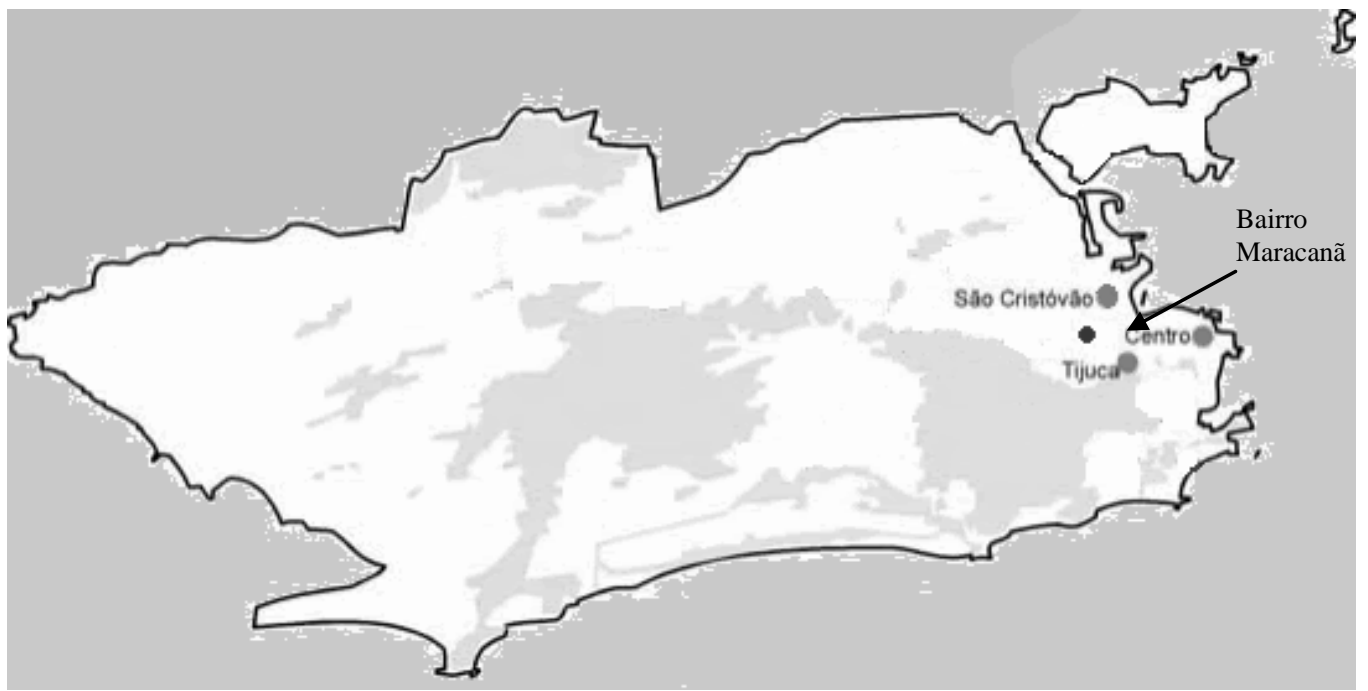

Figura 2 - Localização das estações de qualidade do ar da Prefeitura do Rio de Janeiro

Terceira etapa: monitoramento da temperatura do ar em diferentes ambientes no interior do Estádio Mário Filho. Neste trabalho de campo realizado dentro das dependências do Estádio Mário Filho, (popularmente conhecido como Maracanã), buscou-se avaliar a possível interferência provocada por uma grande concentração de pessoas na temperatura do ar. Para isto, foi escolhido o primeiro jogo da final da Copa do Brasil entre Flamengo e Vasco (dia 19/07/2006), que provavelmente atrairia um bom público ao estádio. No entanto, era preciso saber como se comportava a temperatura e umidade relativa com o estádio vazio para depois fazer o confronto com os dados do dia do jogo. Para este experimento utilizou-se cinco data loggers da marca Novus que foram posicionados em quatro diferentes pontos no interior do Estádio e um distante algumas quadras. A localização dos equipamentos de monitoramento dentro do estádio buscou diferentes pontos de concentração de torcedores como também locais mais seguros, já que o estádio se encontrava em obras, com muitas pessoas circulando por suas dependências. Todos os data loggers ficaram dentro de abrigos (figura 3), a um metro e meio de altura, para que não sofressem influência da radiação do solo, ou fossem atingidos diretamente pelos raios do sol e pela chuva. Estes instrumentos foram fundamentais para dar continuidade ao monitoramento dos dados, pois as medições poderiam ser feitas, instantaneamente e por um período maior de tempo. Os data loggers foram aferidos e programados para registrar dados de 10 em 10 minutos, começando às 14 horas do dia 18/07/2006 e se estendendo até as 12 horas do dia 21/07/2006. 

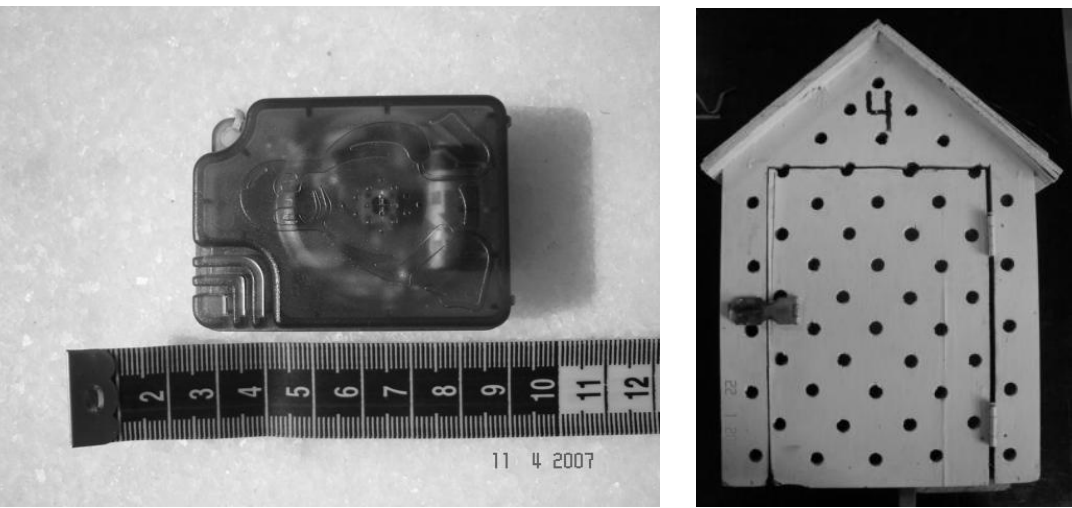

Figura 3 - Data Logger e abrigo utilizados nas medições no Estádio Mário Filho

\section{1 - Os Ambientes Monitorados no Estádio Mário Filho}

A figura 4 mostra a localização dos pontos de monitoramento.

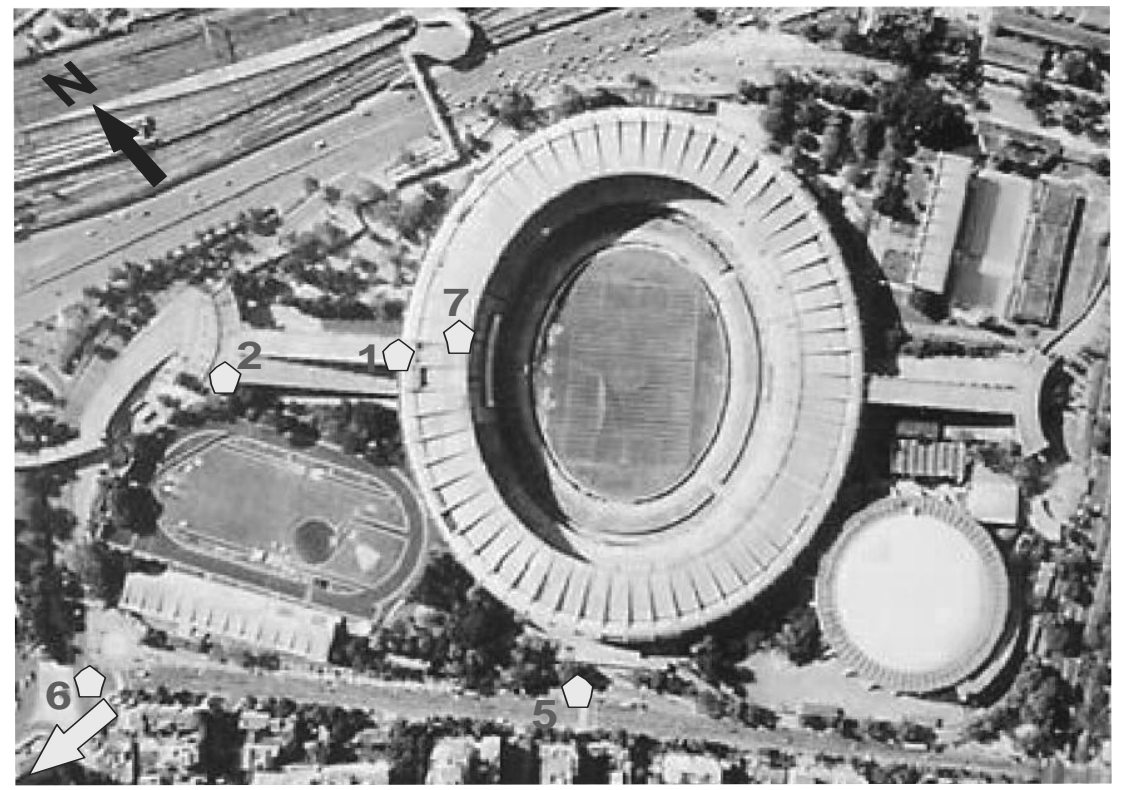

Figura 4 - Localização dos pontos dentro do estádio

Ponto 1: Na Varanda da Suderj, correspondente ao quinto andar, localizado sobre a rampa de acesso as arquibancadas da torcida do Vasco, na direção da Radial Oeste.

Ponto 2: Na parte externa da rampa que dá acesso aos camarotes (passagem de veículos). Este abrigo ficou na altura da copa das árvores, a 15 metros de altura do solo em relação ao primeiro pavimento e, a um metro do segundo pavimento.

Ponto 5: Na portaria social do Maracanã, sobre a cabine da segurança do portão número 19 do estádio, localizado na rua Eurico Rabelo. 
Ponto 6: Na varanda da minha casa, localizada em uma vila de casas, na rua Oito de Dezembro, a uma distância de aproximadamente 1 quilômetro do estádio.

Ponto 7: Próximo as cadeira especiais, no último pavimento das arquibancadas sobre a torcida do Vasco.

\section{Resultados e Discussão}

\section{1 - Os Dados da Estação Meteorológica}

A estação meteorológica Maracanã, apesar de dispor de uma série temporal curta para esta análise, com apenas dez anos, pode-se notar através da figura 5 que a temperatura média anual apresentou uma forte tendência ao aumento, principalmente até o ano de 1997. Enquanto no ano de 1992 a temperatura média anual registrou valor inferior a $25,5^{\circ} \mathrm{C}$, em 2001 este valor foi de $27,5^{\circ} \mathrm{C}$, confirmando a tendência ao aumento.

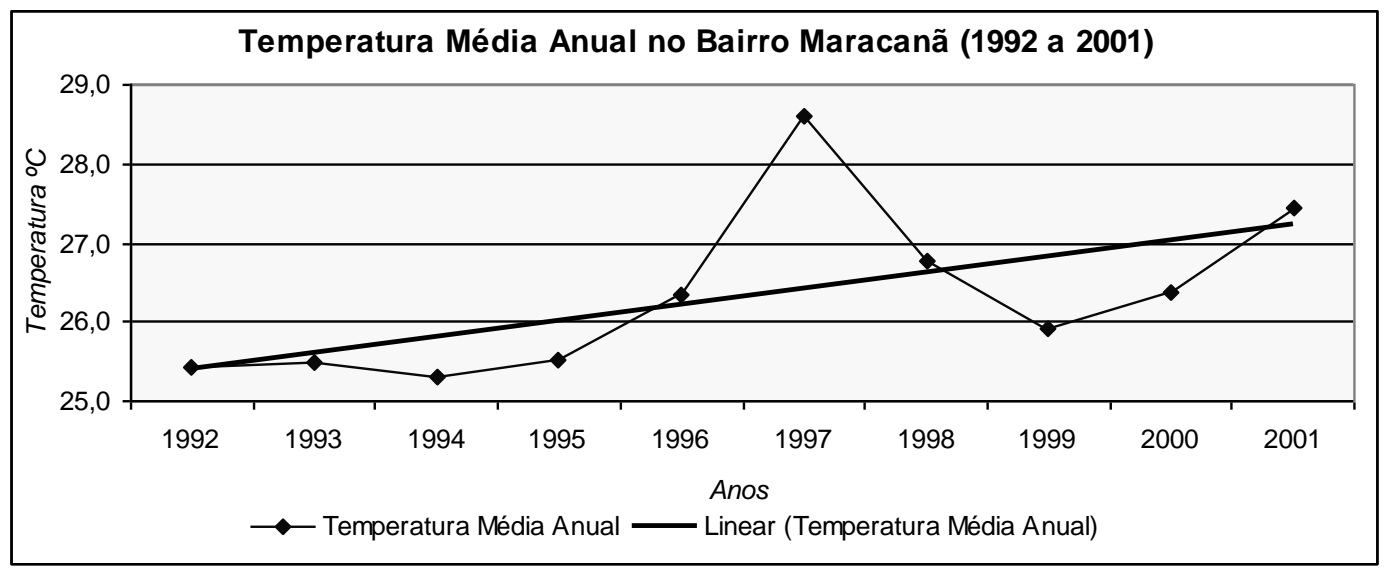

Figura 5 - Temperatura média anual da estação meteorológica do Maracanã

A temperatura média do período foi de $26,1^{\circ} \mathrm{C}$, sendo que cinco dos dez anos da série tiveram temperatura média superior à média do período - 1996, 1997, 1998, 2000 e 2001. O ano de 1997 foi um ano padrão extremo, pois apresentou médias mensais muito altas e, como conseqüência, a temperatura média anual muito superior aos demais anos.

$\mathrm{Na}$ série de dados diários trabalhados de janeiro de 1992 a março de 2002, extraindo-se a média da temperatura para cada dia da semana, encontrase valores mais baixos para os finais de semana (sábado e domingo), enquanto os maiores valores são registrados às terças e quartas feiras, como pode ser observado na figura 6 . Acredita-se que por mais que sejam cumpridas todas as medidas para isolar os efeitos do urbano no registro da temperatura do ar em uma estação meteorológica, pode ser possível que estes se manifestem.

Observando-se os dados de temperatura média anual por dia da semana, para cada ano da série, destacam-se os anos 1994, com as médias mais baixas e 2000 com médias mais elevadas, ambos com um padrão semanal bem evidente, onde o sábado e o domingo têm as temperaturas médias mais baixas da semana. Este comportamento foi também observado nos anos de 1995, 1996, 1999 e 2002. 


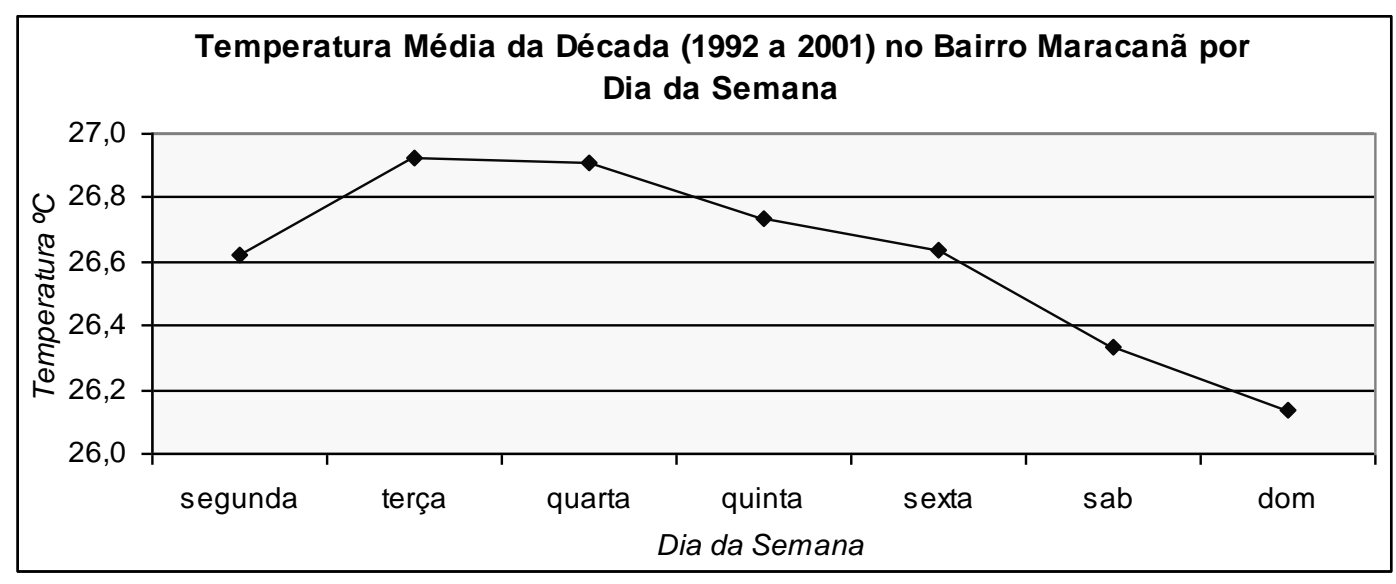

Figura 6 - Temperatura média da década por dia da semana da estação meteorológica do Maracanã

Mas será que esta é uma tendência em toda a Cidade do Rio de Janeiro? No subcapítulo 3.2 foram utilizados os dados de estações meteorológicas de alguns bairros próximos ao Maracanã para verificar o comportamento da temperatura.

\section{2 - Os Dados das Estações de Qualidade do Ar}

As estações de qualidade do ar da Prefeitura do Rio de Janeiro fizeram parte de um projeto da Secretaria Municipal de Meio Ambiente que visava o monitoramento, em tempo real, de partículas inaláveis e elementos do clima, a fim de orientar ações que melhorassem a qualidade do ar na cidade. A série de dados que já é muito curta, devido à duração do projeto (apenas 5 anos de dados registrados, entre 2001 e 2006), ficou ainda menor com as dificuldades para obtê-los junto à Prefeitura.

Foram trabalhados os registros de 2002 das estações de qualidade do ar, sendo o primeiro trimestre deste ano (janeiro, fevereiro e março) o período em comum nas séries de dados tanto da estação do Maracanã quanto da Prefeitura. Para fazer esta comparação foram utilizadas as médias diárias de temperatura das estações de qualidade do ar de São Cristóvão, Tijuca e Centro, apresentados na figura 7.

As três estações apresentam comportamento semelhante para a temperatura média separada por dia da semana, tendo apresentado menores valores aos sábados e domingos nos três bairros. Muito provavelmente estas curvas sejam reflexo do próprio ritmo da cidade, mais agitado de segunda a sexta. As curvas de São Cristóvão e Tijuca são muito parecidas, onde a quartafeira destaca-se como o dia mas quente da semana, no entanto a Tijuca apresentou maiores valores de temperatura e, também, maior amplitude térmica devido a sua posição a sotavento do maciço da Tijuca.

Em São Cristóvão, bairro próximo ao mar, estava menos quente e a amplitude térmica foi menor. Já no Centro o dia mais quente foi a sexta-feira, dia mais agitado na área central da cidade, no entanto, todos os dias úteis (de segunda a sexta-feira) estiveram com médias próximas, variando em no máximo $0,3^{\circ} \mathrm{C}$. No Centro, também, verificou-se maior redução térmica na passagem da sexta para o sábado. 


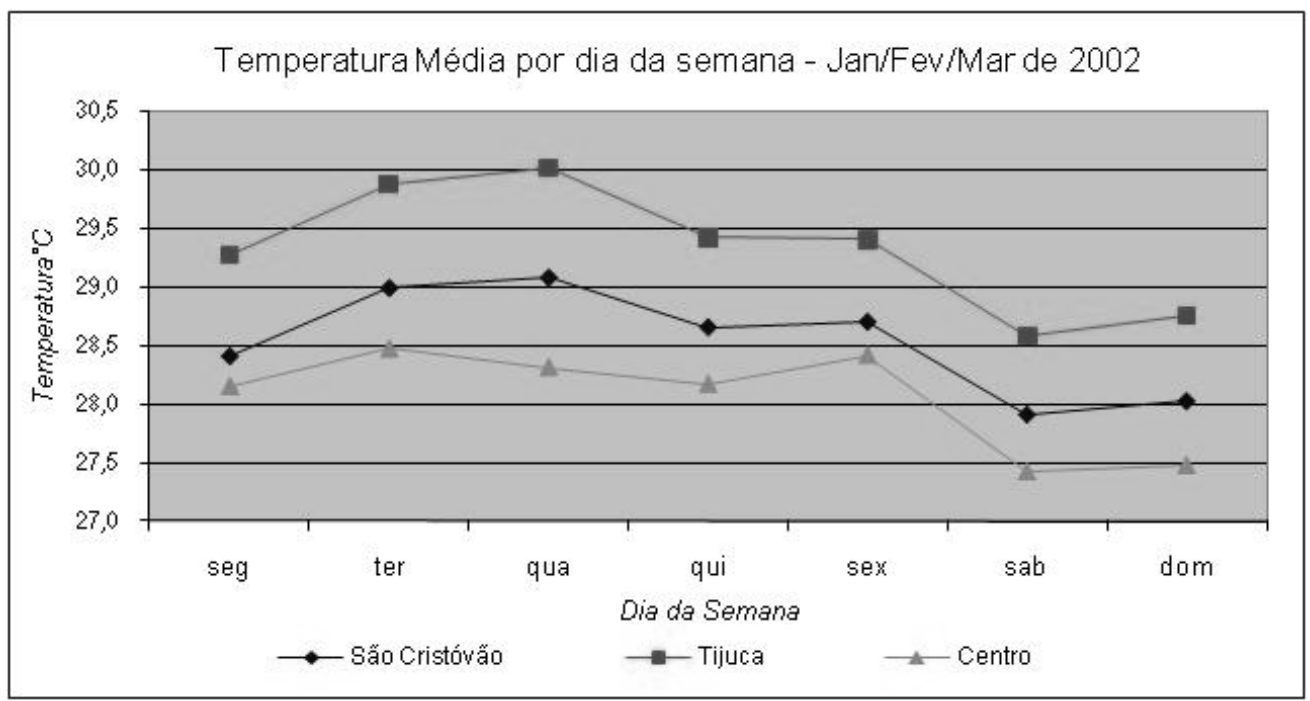

Figura 7 - Temperatura média por dia da semana de 2002 (Estações de Qualidade do Ar)

A tendência ao aquecimento nos dias úteis se repete também nos bairros próximos, de acordo com a série de dados disponíveis. Será que esta evolução semanal da temperatura é uma influência das atividades antrópicas? Buscando identificar correlações entre as atividades passíveis de modificar 0 comportamento da temperatura do ar, foram utilizados dados de monóxido de carbono para verificar se o fluxo de carros, maior em alguns dias da semana, é capaz de influenciar os dados da estação.

\section{3 - Estações de Qualidade do Ar: Temperatura x CO}

Das Estações de Qualidade do Ar da Prefeitura também foram conseguidos os dados das médias diárias e da emissão máxima e média diária de monóxido de carbono (CO), para o mesmo período analisado do ano de 2002. Desta maneira a concentração média, em partes por milhão de CO, por dia da semana foi utilizada como um indicador da intensidade do fluxo de veículos para a comparação com a evolução semanal da temperatura.

Os dados da estação do bairro São Cristóvão apontaram uma maior concentração de CO no sábado e na sexta-feira (figura 8). No entanto, a curva de concentração de $\mathrm{CO}$ não foi acompanhada pela curva de temperatura, como esperado, ou seja, não foi capaz de influenciar a evolução térmica.

$\mathrm{Na}$ estação do bairro Tijuca foram registradas tanto as temperaturas médias mais elevadas como também as maiores concentrações de $\mathrm{CO}$, como mostra a figura 9. As maiores concentrações de CO acontecem na sexta-feira, já que este dia é o de maior movimento de carros e de congestionamentos em toda a cidade. No entanto, assim como ocorreu em São Cristóvão, na Tijuca as médias de temperatura não foram influenciadas pelo ritmo do fluxo de veículos. 


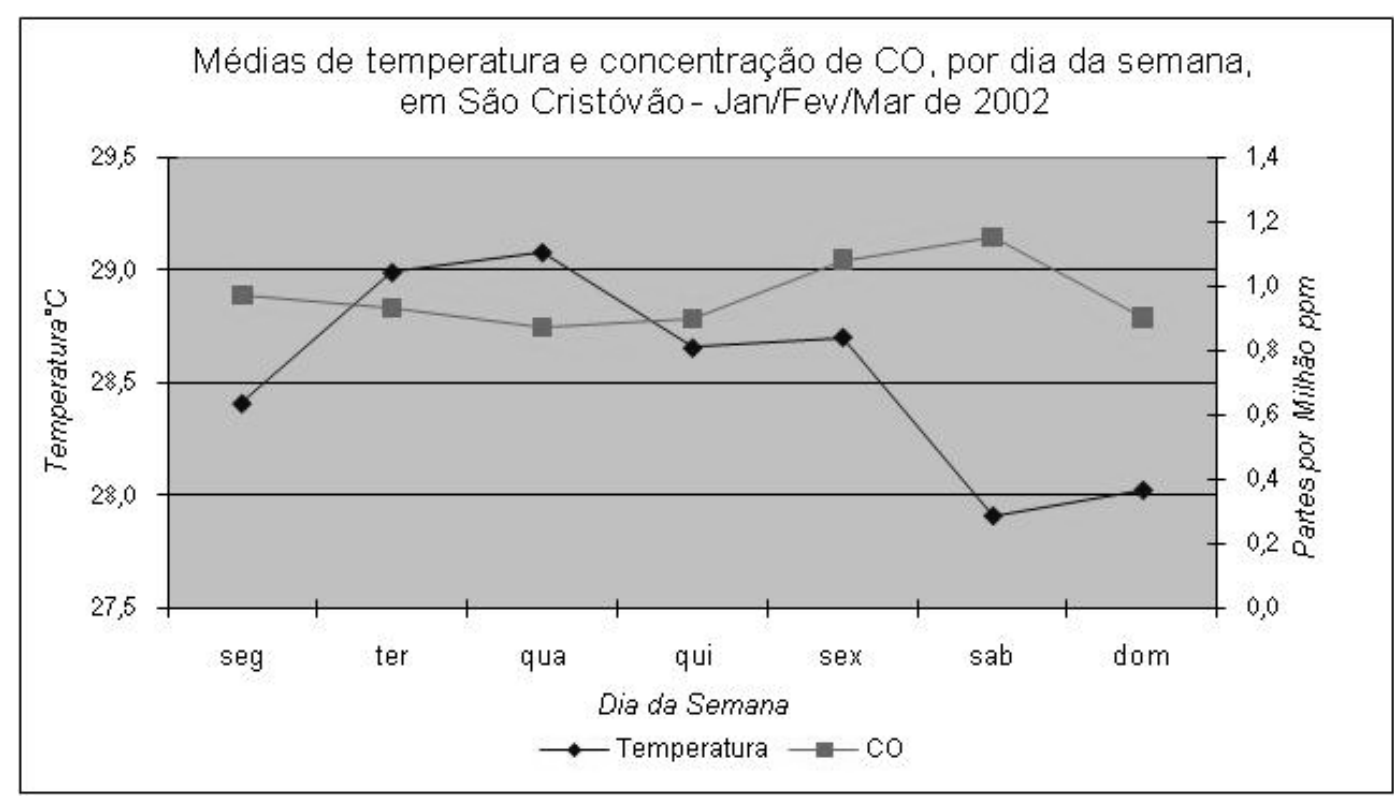

Figura 8 - Média da temperatura e concentração de CO em São Cristóvão

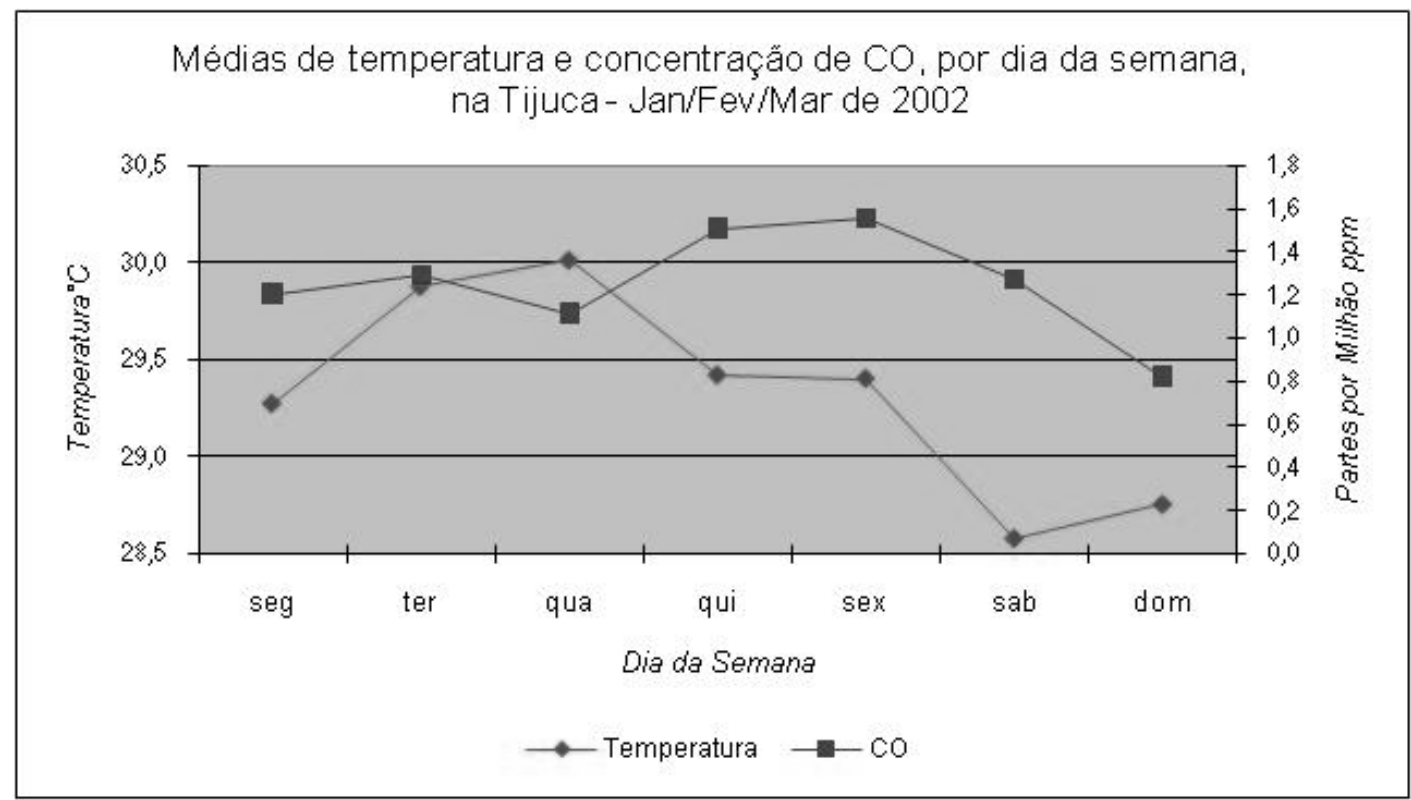

Figura 9 - Média da temperatura e concentração de CO na Tijuca

Na estação do Centro os dados da concentração de CO refletem bem o ritmo do bairro, pois de segunda-feira à quinta-feira há uma constante, que é afetada na sexta-feira, justamente quando o trânsito fica caótico, também, neste bairro como mostra a figura 10. Aos sábados, os escritórios não funcionam e aos domingos quase tudo está fechado, diminuindo bastante o movimento do Centro o que justifica o grande declínio da concentração de CO nos finais de semana. 


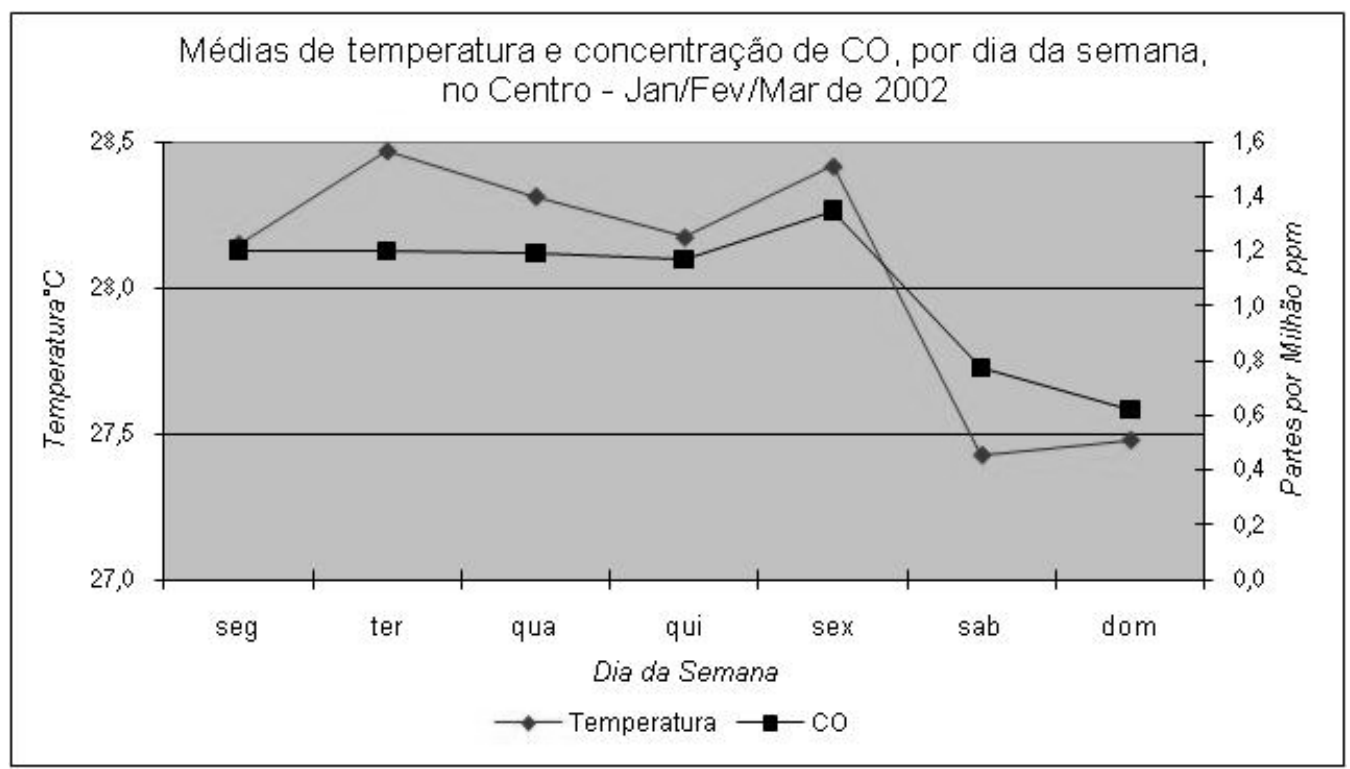

Figura 10 - Média da temperatura e concentração de CO no Centro

Neste bairro, os ritmos de temperatura e concentração de CO apenas em parte, são coincidentes, pois apesar de apresentarem sábado e o domingo como os dias de menor movimento e menor temperatura, durante os demais dias da semana a curva de temperatura não é homogênea como a curva do monóxido de carbono.

No subcapítulo 3.4 a investigação se aprofundou na escala microclimática, analisando os espaços internos do Estádio Mario Filho para avaliar se a concentração de pessoas é responsável por alterar o ritmo da temperatura.

\section{4 - Experimento no Estádio Mário Filho}

Nos dias 18, 19, 20 e 21/07/2006 as condições atmosféricas sobre a cidade eram de predomínio do Anticiclone Subtropical do Atlântico, garantindo tempo bom e temperatura variando entre 17 a $30^{\circ} \mathrm{C}$ durante o experimento. Com base nos dados obtidos com os data loggers visualizou-se resultados interessantes da curva de temperatura no Estádio durante o evento ocorrido no dia 19.

Nos dados de temperatura registrados pelos data loggers, continuamente nos cinco pontos de monitoramento dentro e fora do estádio Mário Filho, desde às 14 horas do dia 18 de julho até às 12 horas do dia 21 de julho, destaca-se que:

Em dois dos pontos de observação os abrigos onde estavam os data loggers ficaram expostos aos raios do sol, a rampa da arquibancada (P1) e área afastada (P6), apresentando as temperaturas mais elevadas no início da tarde.

O ponto 6 (área afastada) ficou em uma vila distante um quilometro do Estádio Maracanã. Sem a presença de grandes edificações que obstruam a passagem dos ventos, este ponto, que ficou muito exposto, mas também é 
bastante ventilado, apresenta um aquecimento abrupto no início da manhã e uma queda da temperatura a tarde.

O ponto 1 (rampa da arquibancada), apesar de ficar o abrigo exposto ao sol, não está em uma área aberta, o que dificulta o seu resfriamento. O ponto 2 (rampa do camarote) ficou próximo a copa das árvores, a 15 metros do solo, altura alcançada pela rampa. Estes fatores podem justificar a temperatura mais reduzida registrada durante a tarde, mesmo tendo também ficado em uma área exposta aos raios solares.

Os pontos 5 e 7, relativos a portaria social e a torcida, respectivamente, ficaram dentro do estádio em áreas cobertas o que justifica as pequenas amplitudes térmicas diária verificadas nos dois pontos.

A noite do dia 19/07/2006 foi o momento mais esperado, pois os times do Flamengo e do Vasco disputavam o primeiro jogo da final da Copa do Brasil e, suas torcidas prometiam encher o estádio que estava sendo monitorado pelos data loggers e pela equipe de estudo.

Apesar de ter sua capacidade reduzida, em conseqüência das obras que objetivam adequar o estádio às exigências da FIFA, o público presente foi superior a 50.000 pessoas. Para avaliar se houve a influência da concentração de pessoas no comportamento da temperatura, nos diferentes pontos, pode-se observar a temperatura do ar registrada no dia 19/07/2006, próximos ao horário da partida (figura 11).

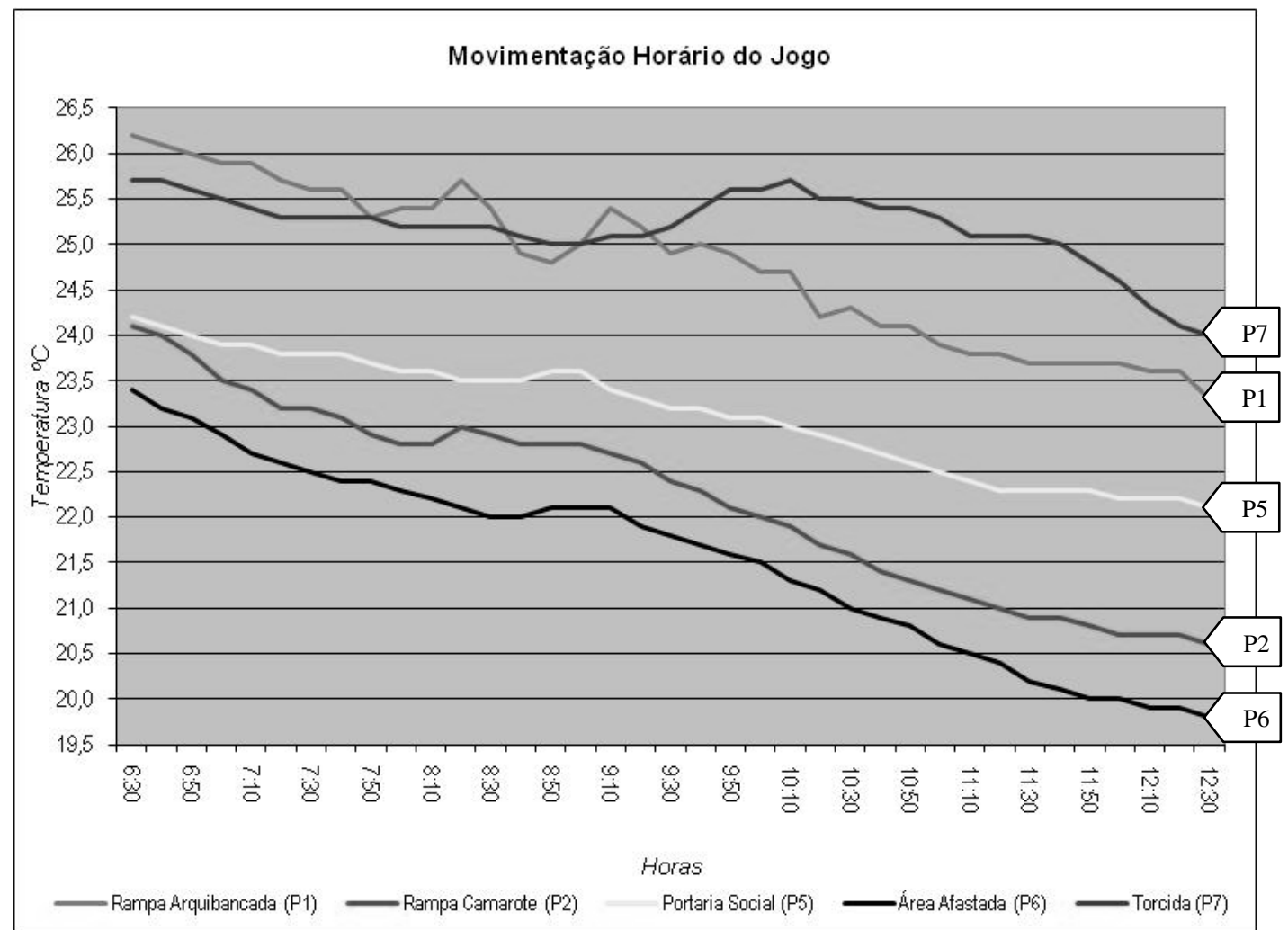

Figura 11 - Temperatura do Ar nas Horas Próximas ao Jogo do dia $19 / 07 / 2006$ 
A figura 11 mostra as temperaturas do monitoramento no dia do jogo. Notadamente, embora a abertura dos portões que dão acesso ao estádio ocorresse às 18:30 horas, as alterações nas curvas de temperatura se iniciaram por volta das 20 horas e terminam perto das 00:30. No gráfico nota-se que as temperaturas dos cinco pontos estão em queda, entretanto percebe-se uma alteração em todos os pontos durante a descendência. 0 ponto 7 apresenta maior irregularidade a partir das 21:30 horas.

Por se destacarem dos demais, os pontos 1 e 7 foram analisados separadamente, comparando-os com a linha de tendência de cada um. A figura 12 mostra que no ponto 1 às $20: 10$ horas a temperatura registrada foi de $25,4^{\circ} \mathrm{C}$, alcançando o primeiro pico às $20: 20 \mathrm{com} 25,7^{\circ} \mathrm{C}$, e, volta a cair às $20: 30$ horas para $25,4^{\circ} \mathrm{C}$. Às $20: 40$ horas a temperatura desce para $24,9^{\circ} \mathrm{C}$ e na marcação seguinte, $20: 50$ horas, cai para $24,8^{\circ} \mathrm{C}$. Às $21: 00$ horas a temperatura volta a $25,0^{\circ} \mathrm{C}$, com um novo pico de $25,4^{\circ} \mathrm{C}$ às $21: 10$ horas.

Na figura 13 mostra que no ponto 7 a temperatura do ar vai diminuindo até às $21: 00$ horas, quando atinge $25,0^{\circ} \mathrm{C}$. As $21: 10$ horas novamente registrase $25,0^{\circ} \mathrm{C}$ e, a partir deste horário a temperatura torna a elevar-se alcançando os valores de $25,6^{\circ} \mathrm{C}$ as $21: 50$ horas, com o máximo registrado as 22:10 horas, de 25,70 . Depois deste horário a temperatura volta a cair, num ritmo bem mais lento, retomando os $25,0^{\circ} \mathrm{C}$ somente as $23: 40$ e, a partir deste momento tem uma queda mais acelerada de $0,2^{\circ} \mathrm{C}$ a cada 10 minutos.

O horário de alteração da curva coincide com o horário e o período de duração do evento, descrito anteriormente, quando foi atingida a concentração máxima de pessoas nas arquibancadas do estádio. Ao comparar a temperatura máxima registrada durante a partida com o início do aquecimento percebe-se uma elevação de quase $1^{\circ} \mathrm{C}$ na temperatura onde localizou-se o ponto 7.

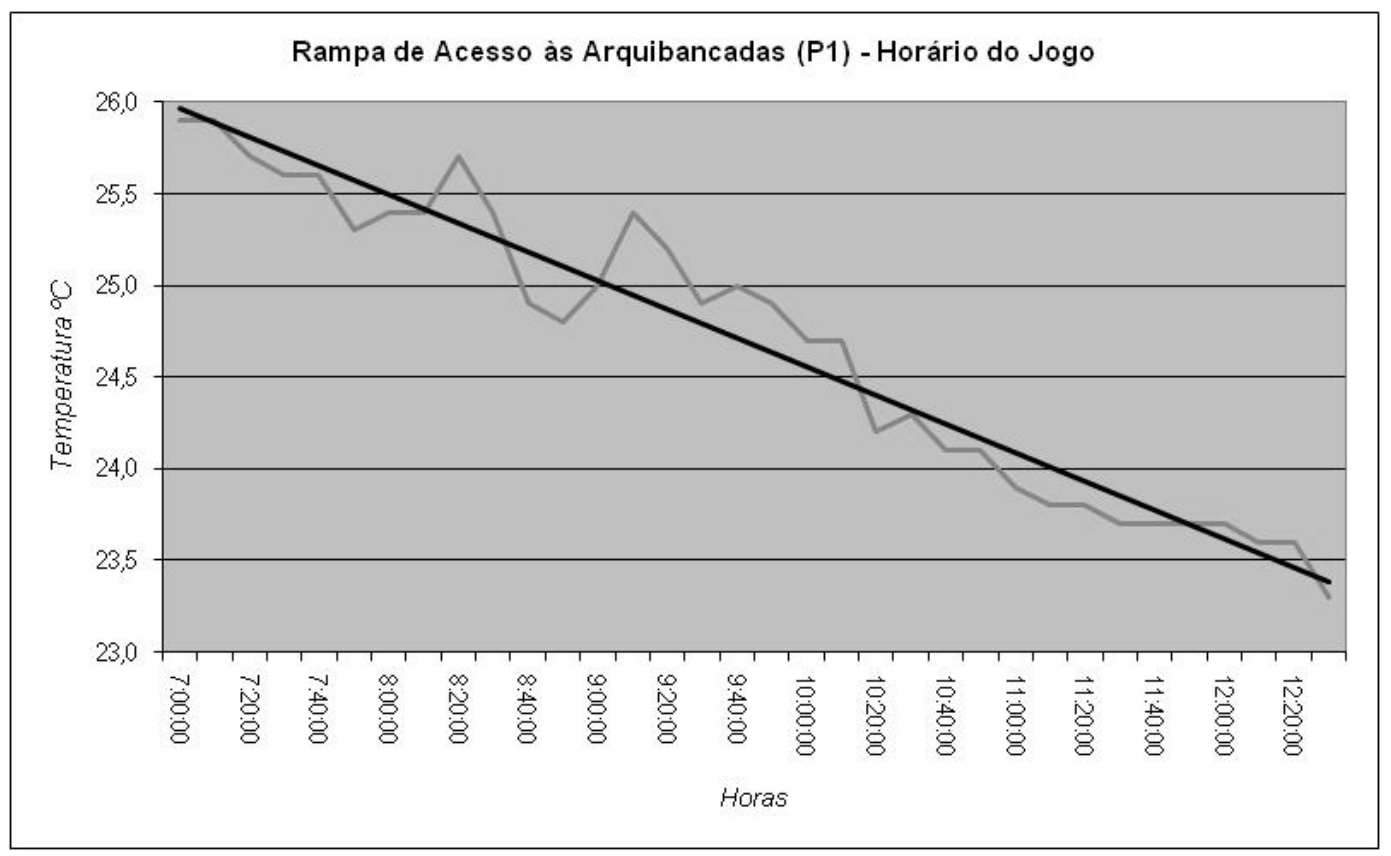

Figura 12 - Temperatura do ar no ponto 1 a realização do evento 


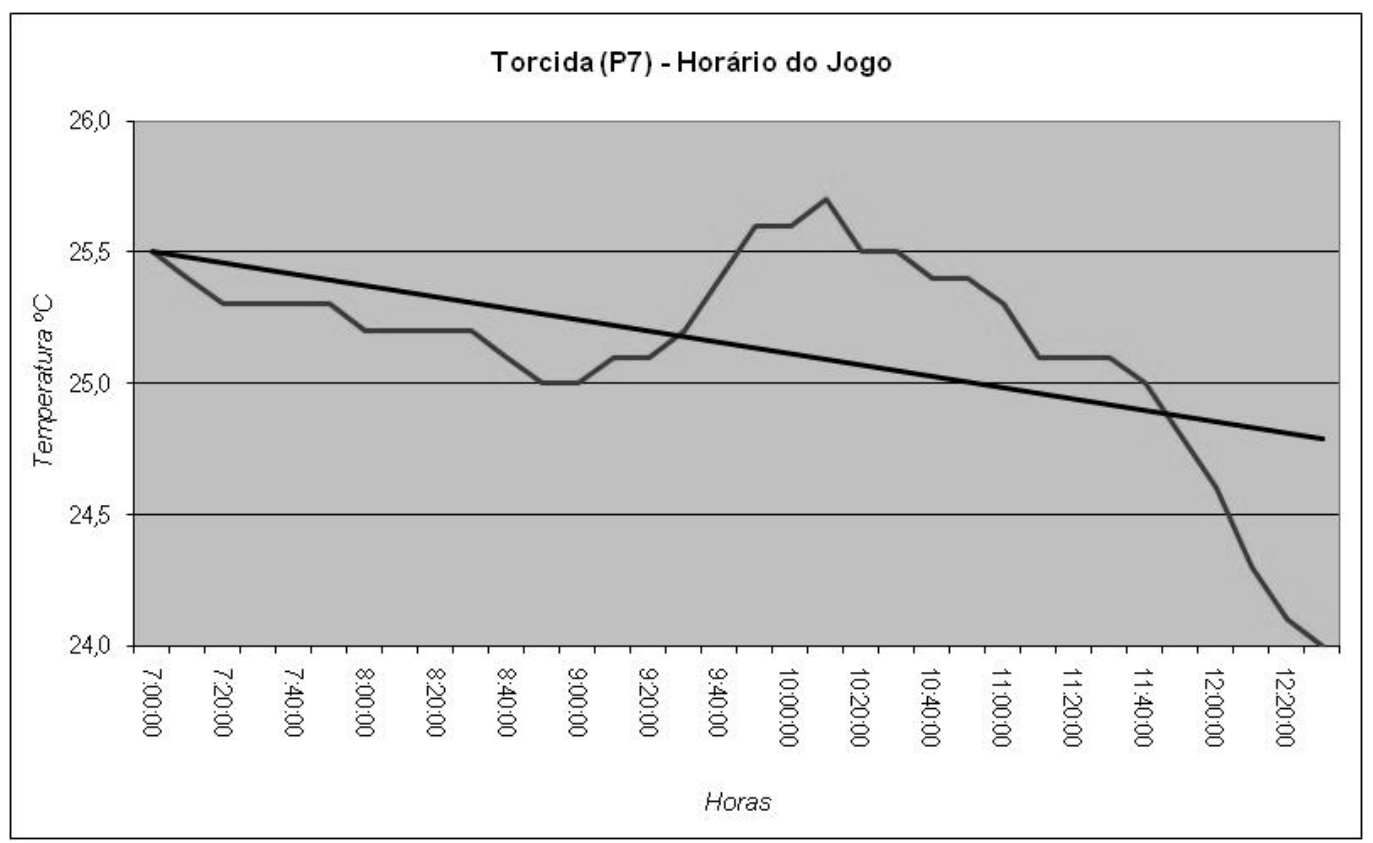

Figura 13 - Temperatura do ar no ponto 7 durante a realização do evento

\section{CONCLUSÕES}

As hipóteses levantadas a partir dos questionamentos apresentados foram investigadas e parcialmente comprovadas. Nas etapas iniciais verificou-se a existência de uma evolução semanal da temperatura do ar nos dados do período que compreende janeiro de 1992 à março de 2002 da estação meteorológica do Maracanã, como também nos dados correspondentes ao primeiro trimestre de 2002 das estações da Tijuca, São Cristóvão e Centro. Nestes bairros a temperatura se eleva a partir da segunda-feira, atingindo o máximo na terça e na quarta-feira, diminuindo na quinta e sexta-feira, até alcançar as temperaturas mais baixas no sábado e no domingo, indicando que este ritmo semanal, provavelmente, esteja relacionado a própria escala da cidade do Rio de Janeiro.

A partir das similaridades do comportamento observado nos gráficos construídos com os dados das estações meteorológicas, tentou-se comprovar a hipótese de que este ritmo da temperatura é influenciado por atividades antrópicas. Na etapa que avaliou o ritmo semanal como um reflexo da concentração de veículos, devido a liberação de gases estufa na queima de combustíveis fósseis, não foi encontrada relação significativa entre os dados médios diários de temperatura e de concentração de monóxido de carbono.

Ainda que os dados utilizados nesta etapa correspondam a um período curto, estes não foram capazes de confirmar a hipótese de interferência dos veículos na temperatura. Isso porque em bairros como a Tijuca e São Cristóvão a curva da temperatura não foi influenciada pelo comportamento da curva de concentração do monóxido de carbono. 
Esta tendência, onde valores mais baixos tanto de temperatura quanto de concentração de CO são encontrados nos finais de semana, foi observada no Centro que tem um ritmo semanal bem marcante, dada as características das atividades comerciais e de serviços ali preponderantes. No entanto as oscilações da curva de temperatura durante os dias úteis não foram acompanhadas pela curva de concentração de CO que estava mais homogênea. Diante desta pequena divergência observada entre as curvas conclui-se que apesar de os ritmos verificados no Centro confirmarem a hipótese levantada, esta etapa necessita de estudos específicos mais detalhados para se chegar a conclusões mais seguras.

A última etapa, de monitoramento da temperatura dentro do estádio por quatro dias consecutivos, com um grande evento ocorrendo neste intervalo, confirmou a hipótese de que grandes aglomerações de pessoas interferem na temperatura em microescala, além das redondezas próximas, como indicaram os data loggers.

Durante a primeira partida da final da Copa do Brasil, disputada entre Flamengo e Vasco no Maracanã, diante de um público superior a 50 mil pessoas, as curvas de temperatura de todos os data loggers registraram uma "perturbação", mesmo no ponto localizado a um quilômetro de distância do estádio. $\mathrm{O}$ instrumento que registrou maior interferência na temperatura estava localizado próximo à torcida em uma área aberta, e apontou uma elevação de $1^{\circ} \mathrm{C}$ aproximadamente.

O aumento de temperatura verificado próximo a torcida correspondeu à uma situação extrema de concentração de pessoas em micro escala. Assim, a participação da concentração de pessoas deve corresponder a uma pequeníssima parcela do calor registrado na estação meteorológica. Isso porque é significativa a contribuição de outros fatores, tais como: uso do solo, altura das edificações, confluência de vias de circulação, traçado urbano e arborização urbana que são responsáveis pela existência de um clima com características específicas de área urbana e refletem suas influências nos dados das estações meteorológicas. Por mais que sejam cumpridas todas as medidas para isolar os efeitos do urbano no registro da temperatura, pode ser possível que estes se manifestem.

Desta maneira apesar dos resultados da terceira etapa, que avaliou a interferência da concentração de CO na temperatura, refutar a influência das atividades na evolução semanal da temperatura na escala local, há a ressalva de que uma série com melhor quantidade e qualidade nos dados possa indicar o contrário.

Entretanto o próprio relatório do Painel Intergovernamental de Mudanças Climáticas (IPCC) faz ressalvas quanto as divergências entre as forças que intervêm no clima nas pequenas escalas, pois apesar apontar $0 \mathrm{CO}_{2}$ como $\mathrm{o}$ grande vilão do aquecimento global e, que os veículos têm contribuído no lançamento deste gás, o mesmo documento indica que há uma exceção para as menores escalas. Nas menores escalas a "variação natural do clima é relativamente maior devido a forças externas. Incertezas com relação às forças locais e feedbaks também tornam difícil estimar a contribuição do aumento do gás estufa na mudança de temperatura em escala menor". (IPCC, 2007:10) 


\section{REFERÊNCIAS BIBLIOGRÁFICAS}

AZEVEDO, T. R. Derivação antrópica do clima da Região Metropolitana de São Paulo abordada como função do ritmo semanal das atividades humanas. São Paulo. Departamento de Geografia. FFLCH/USP. Tese de Doutorado. 2001.

BRANDÃO, A. M. P. M. As Alterações Climáticas na Área Metropolitana do Rio de Janeiro: uma provável influencia do clima urbano. In: ABREU, M. DE A. (org.).: Natureza e sociedade no Rio de Janeiro. Rio de Janeiro: Secretaria Municipal de Cultura, Turismo e Esporte. 1992. p.143-200.

BRANDÃO, A. M. P. M. O Clima Urbano da Cidade do Rio de Janeiro. Departamento de Geografia. FFLCH/USP. Tese de Doutorado. São Paulo. 1996.

INTERGOVERNAMENTAL PANEL ON CLIMATE CHANGE. Climate Change 2007: The Physical Sciense Basis. Summary for Policymakers. Contribuition of Working Group I to the Fourth Assessment Report of the Intergovernamental Panel on Climate Change. Disponível em www.ipcc.ch.

LOMBARDO, M.A. A Ilha de Calor nas Metrópoles: O Exemplo de São Paulo. São Paulo. HUCITEC, 1985. 244p.

MENDONÇA, F. Clima e Planejamento Urbano em Londrina: Proposição Metodológica e de Intervenção Urbana a partir do Estudo do Campo TermoHigrométrico. In: MONTEIRO, C. A. F. e MENDONÇA, F. (org).: Clima Urbano. São Paulo. Contexto. 2003. p.93 - 120.

MONTEIRO, C. A. F. Teoria e Clima Urbano. Departamento de Geografia. FFLCH/USP. Tese de Livre-Docência. São Paulo. 1976. 